\title{
Real understanding of the nitrogen-doping effect on the electrochemical performance of carbon materials by using carbon-coated mesoporous silica as a model material
}

\author{
Supporting information \\ Alberto Castro-Muñiz*, Yasuto Hoshikawa, Takatoshi Kasukabe, Hiroshi Komiyama, Takashi \\ Kyotani. \\ Institute of Multidisciplinary Research for Advanced Materials, Tohoku University, 2-1-1 \\ Katahira, Aoba-ku, Sendai 980-8577, Japan. \\ *E-mail alberto@tagen.tohoku.ac.jp
}




\section{Physicochemical properties of carbon-coated SBA-15}
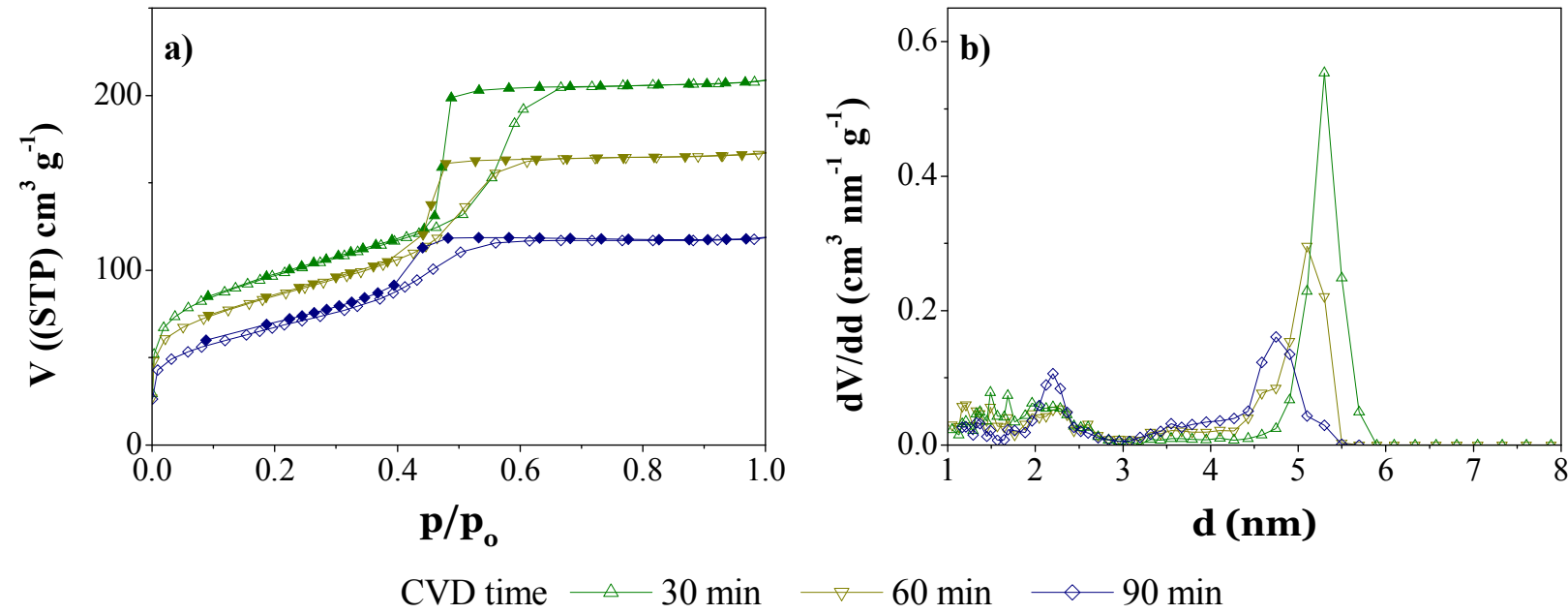

Figure S1. $\mathrm{N}_{2}$ adsorption isotherms at $-196{ }^{\circ} \mathrm{C}$ of acetonitrile carbon-coated SBA-15 samples (a) and their respective DFT pore size distributions (b).
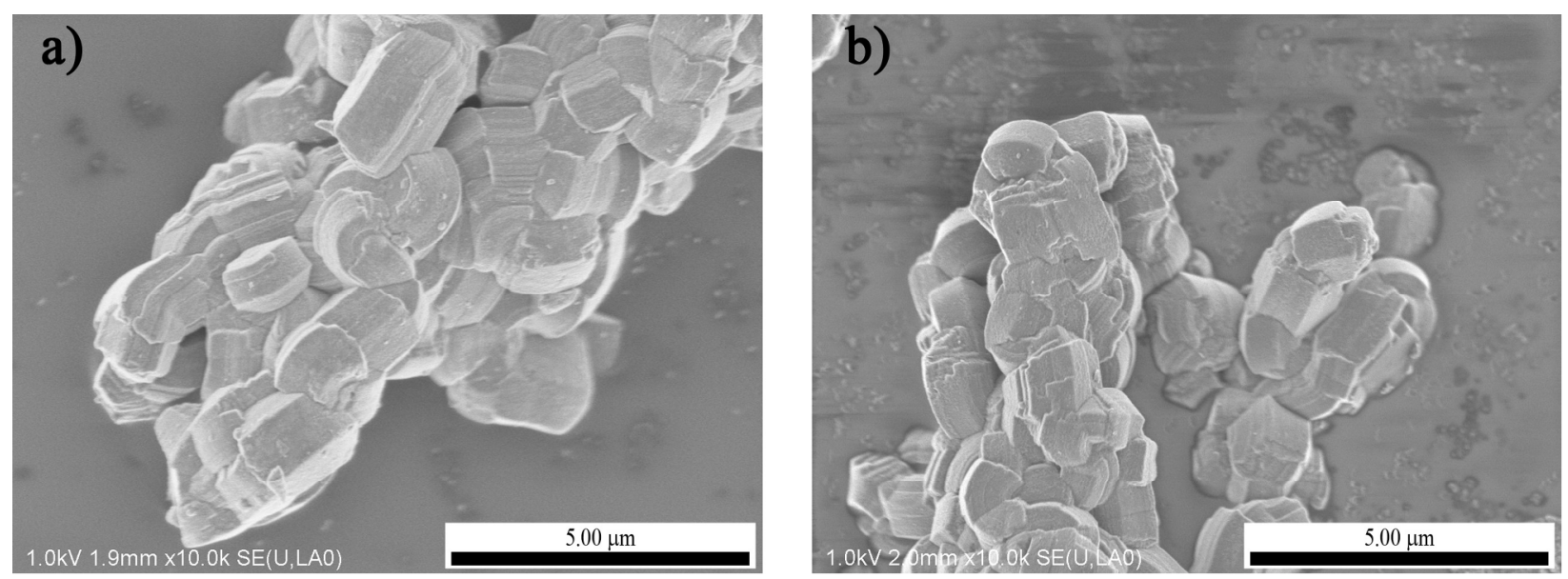

Figure S2. SEM micrographs of CN-SBA15 (a) and C-SBA15 (b). 


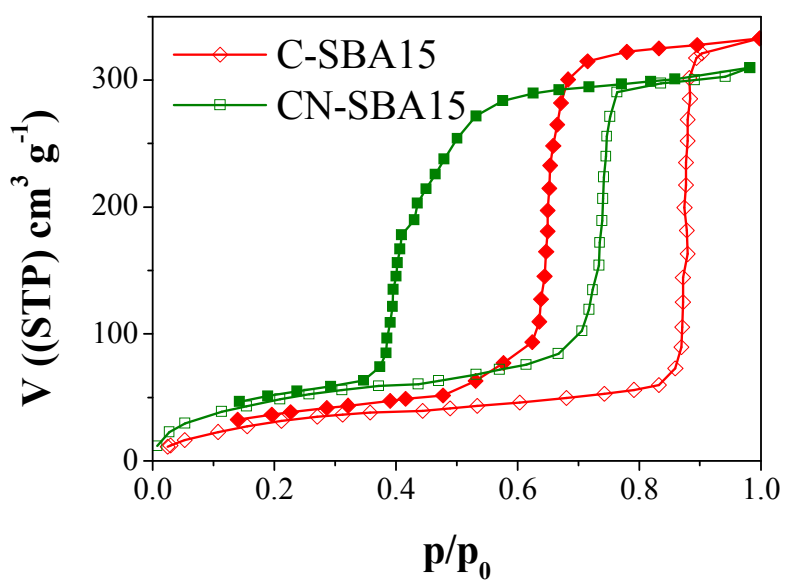

Figure S3. Water vapor adsorption isotherms $\left(25^{\circ} \mathrm{C}\right)$ on the heat-treated carbon-coated SBA- 15 samples (open symbols: adsorption, solid symbols: desorption).

\section{Electrochemical performance}

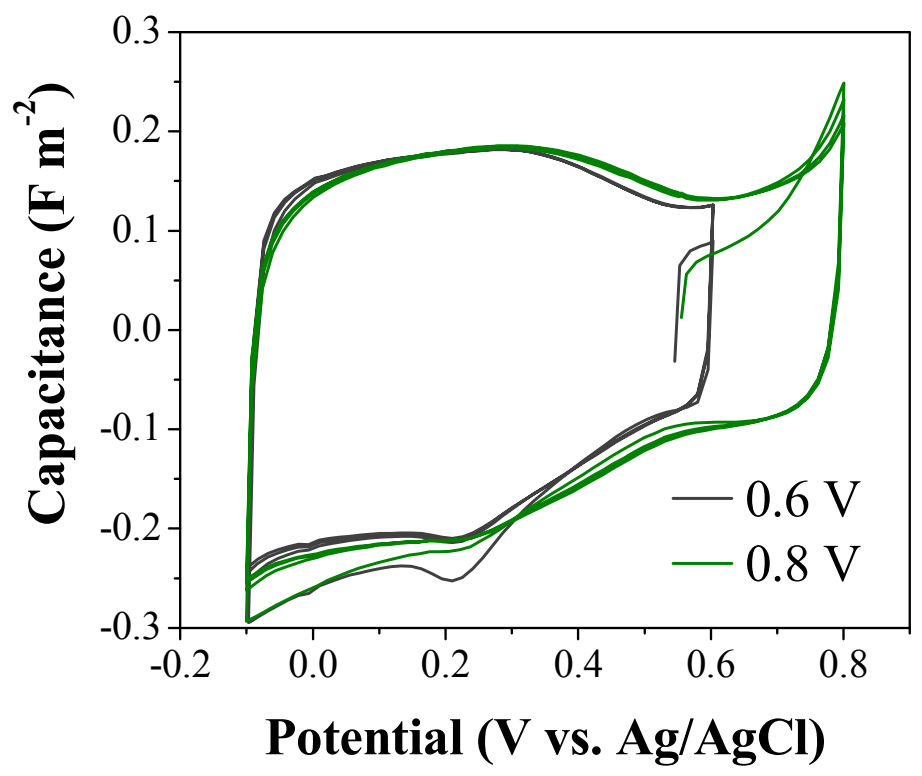

Figure S4. Cyclic voltammograms (sweep rate: $0.5 \mathrm{mV} \mathrm{s}^{-1}$, cycles 1 to 4 ) of nitrogen doped carbon-coated samples measured in $1 \mathrm{M} \mathrm{H}_{2} \mathrm{SO}_{4}$ with two different upper limit potentials $(0.6 \mathrm{~V}$ and $0.8 \mathrm{~V})$. 


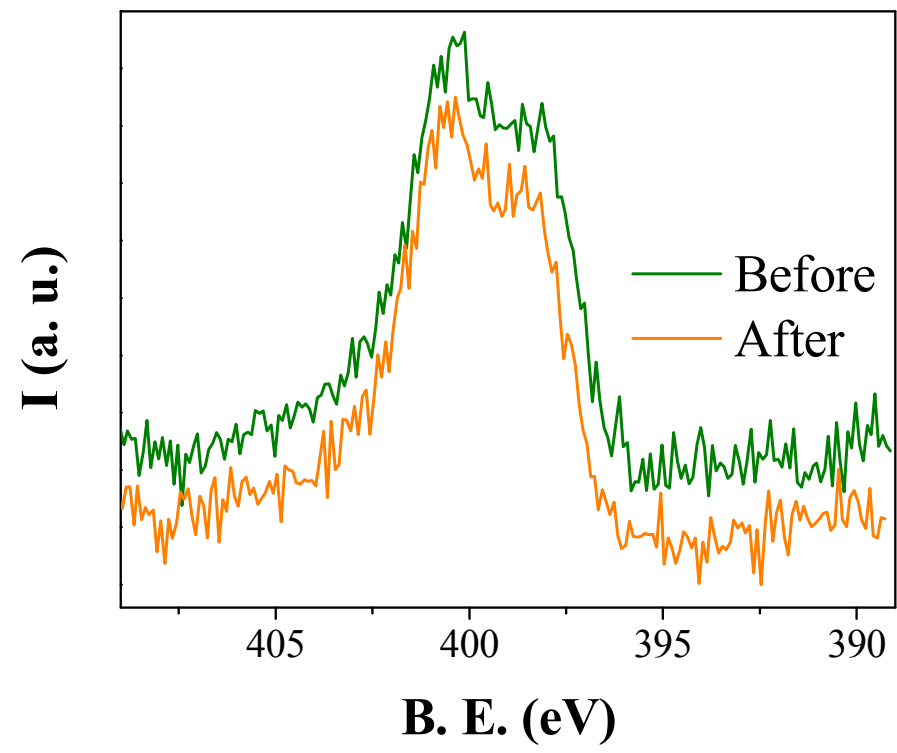

Figure S5. XPS spectra corresponding to $\mathrm{N} 1 \mathrm{~s}$ of the paste prepared with the nitrogen carboncoated SBA-15 used in the electrodes before and after the electrochemical measurements.

Calculation of the number of electrons involved in the redox reactions due to the $\mathrm{N}$ containing surface groups. From the CV cyclic voltammetry we can calculate the total charge as:

$$
Q_{t}=\frac{1}{2} \int_{t_{0}}^{t_{1}} I(t) d t=\frac{1}{2 r} \int_{V_{0}}^{V_{1}} I(V) d V
$$

where $\mathrm{r}$ is the sweep rate. $Q_{t}$ is the total charge in $\mathrm{C}$ then the total number of electrons involved in the redox reactions is:

$$
\mathrm{N}_{\mathrm{e}}=6.241509 \cdot 10^{18} \mathrm{Q}_{\mathrm{t}} \mathrm{e}^{-}
$$

The mass of the samples in the electrodes is known, $\mathrm{m}_{\mathrm{CMPS}}$, so it is possible to obtain the specific number of electrons as: 


$$
\mathrm{n}_{\mathrm{e}}=\frac{\mathrm{N}_{\mathrm{e}}}{\mathrm{r}_{\mathrm{C}} \mathrm{m}_{\mathrm{CMPS}}}
$$

where $r_{C}$ is the ratio of the mass of the carbon layer to the total mass calculated from the TG. On the other side, the $\mathrm{N}$ to $\mathrm{C}$ atomic ratio $\left(\mathrm{r}_{\mathrm{N}}\right)$ obtained from the XPS analysis is:

$$
\mathrm{r}_{\mathrm{N}}=\frac{\mathrm{N}_{\mathrm{at}}}{\mathrm{C}_{\mathrm{at}}} \frac{\mathrm{N} \text { atoms }}{\mathrm{C} \text { atoms }}
$$

The specific number of $\mathrm{N}$ atoms can be calculated as follows:

$$
\begin{aligned}
\mathrm{n}_{\mathrm{N}}=\frac{\mathrm{N}_{\mathrm{at}} \mathrm{N} \text { atoms }}{\mathrm{C}_{\mathrm{at}} \mathrm{C} \text { atoms }+\mathrm{N}_{\mathrm{at}} \mathrm{N} \text { atoms }} \\
\quad=\frac{\mathrm{N}_{\mathrm{at}} \mathrm{N} \text { atoms }}{\mathrm{C}_{\mathrm{at}} \mathrm{C} \text { atoms } \frac{1 \mathrm{~mol} \mathrm{C}}{\mathrm{N}_{\mathrm{A}} \mathrm{C} \text { atoms }} \frac{12 \mathrm{~g}}{1 \mathrm{~mol} \mathrm{C}}+\mathrm{N}_{\mathrm{at}} \mathrm{N} \text { atoms } \frac{1 \mathrm{~mol} \mathrm{~N}}{\mathrm{~N}_{\mathrm{A}} \mathrm{N} \text { atoms }} \frac{14 \mathrm{~g}}{1 \mathrm{~mol} \mathrm{~N}}} \\
=\mathrm{N}_{\mathrm{A}} \frac{\mathrm{N}_{\mathrm{at}} \mathrm{N} \text { atoms }}{\mathrm{C}_{\mathrm{at}} 12 \mathrm{~g} \mathrm{C}+\mathrm{N}_{\mathrm{at}} 14 \mathrm{~g} \mathrm{~N}}=\mathrm{N}_{\mathrm{A}} \frac{\mathrm{N}_{\mathrm{at}} \mathrm{N} \text { atoms }}{\frac{\mathrm{C}_{\mathrm{at}}}{\mathrm{N}_{\mathrm{at}}} 12 \mathrm{~g} \mathrm{C}+14 \mathrm{~g} \mathrm{~N}} \\
=\mathrm{N}_{\mathrm{A}} \frac{\mathrm{N}_{\mathrm{at}} \mathrm{N} \text { atoms }}{\frac{1}{\mathrm{r}_{\mathrm{N}}} 12 \mathrm{~g} \mathrm{C}+14 \mathrm{~g} \mathrm{~N}}
\end{aligned}
$$

The pyridine type N content can be calculated from the XPS deconvolution:

$$
\mathrm{n}_{\mathrm{pyr}}=\mathrm{n}_{\mathrm{N}} \mathrm{r}_{\mathrm{N}}^{\mathrm{pyr}}
$$

Where $\mathrm{r}_{\mathrm{N}}^{\mathrm{pyr}}$ is the ratio of pyridine type nitrogen.

From the experimental data, the number of electrons involved in the redox reactions rose by the $\mathrm{N}$ type surface groups would be:

$$
\mathrm{n}_{\mathrm{e}}=4.4 \times 10^{17} \mathrm{e}^{-} / \mathrm{mg}(\mathrm{C}+\mathrm{N})
$$


From the XPS results $\left(r_{N}=0.054\right.$ at $N /$ at $\left.C, r_{N}^{p y r}=28 \%\right)$, the number of pyridinic nitrogen atoms in the carbon layer is:

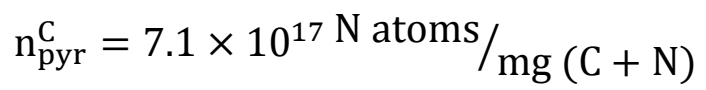

From the $\mathrm{N}_{2}$ adsorption isotherms results analysis, the thickness of the carbon layer was estimated as $0.4 \mathrm{~nm}$. The interlayer spacing between two graphene layers is $0.335 \mathrm{~nm}$, so the average number of carbon layers $\left(\mathrm{n}_{\mathrm{C}}\right)$ is ca. 1.2. From this number of carbon layers, the amount of carbon that would be loaded on the SBA-15 is $22.25 \mathrm{wt} . \%$ which is in agreement with the TG results. Finally, the average number of pyridinic nitrogen atoms on the outer surface of the carbon layer is:

$$
\mathrm{n}_{\mathrm{pyr}}=\mathrm{n}_{\mathrm{pyr}}^{\mathrm{C}} / \mathrm{n}_{\mathrm{C}}=5.9 \times 10^{17 \mathrm{~N} \text { atoms }} / \mathrm{mg}(\mathrm{C}+\mathrm{N})
$$

\section{Electrocatalytic oxygen reduction in neutral media}

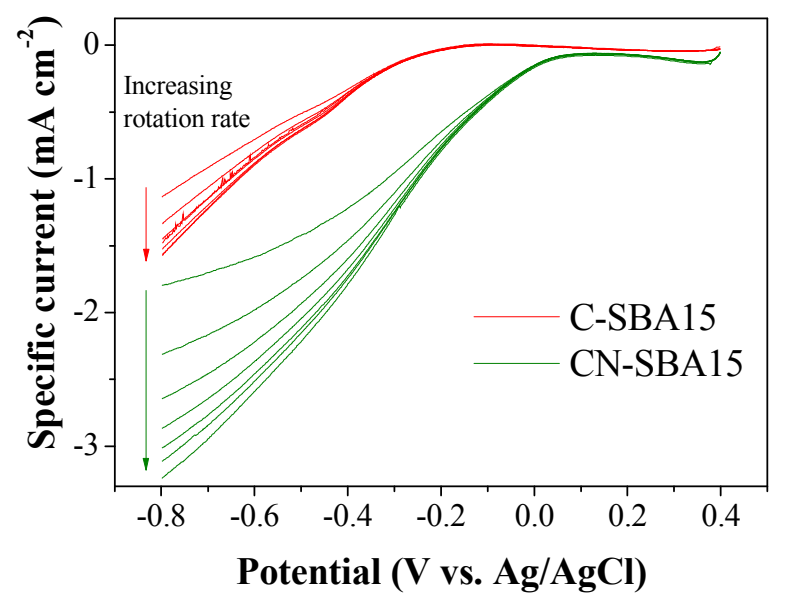

Figure S6. Polarization curves (sweep rate: $10 \mathrm{mV} \mathrm{s}^{-1}$ ) at different rotation rates for the oxygen reduction of the carbon-coated samples in $\mathrm{O}_{2}$-saturated $\mathrm{PBS}$ at $\mathrm{pH} 6.86$. 

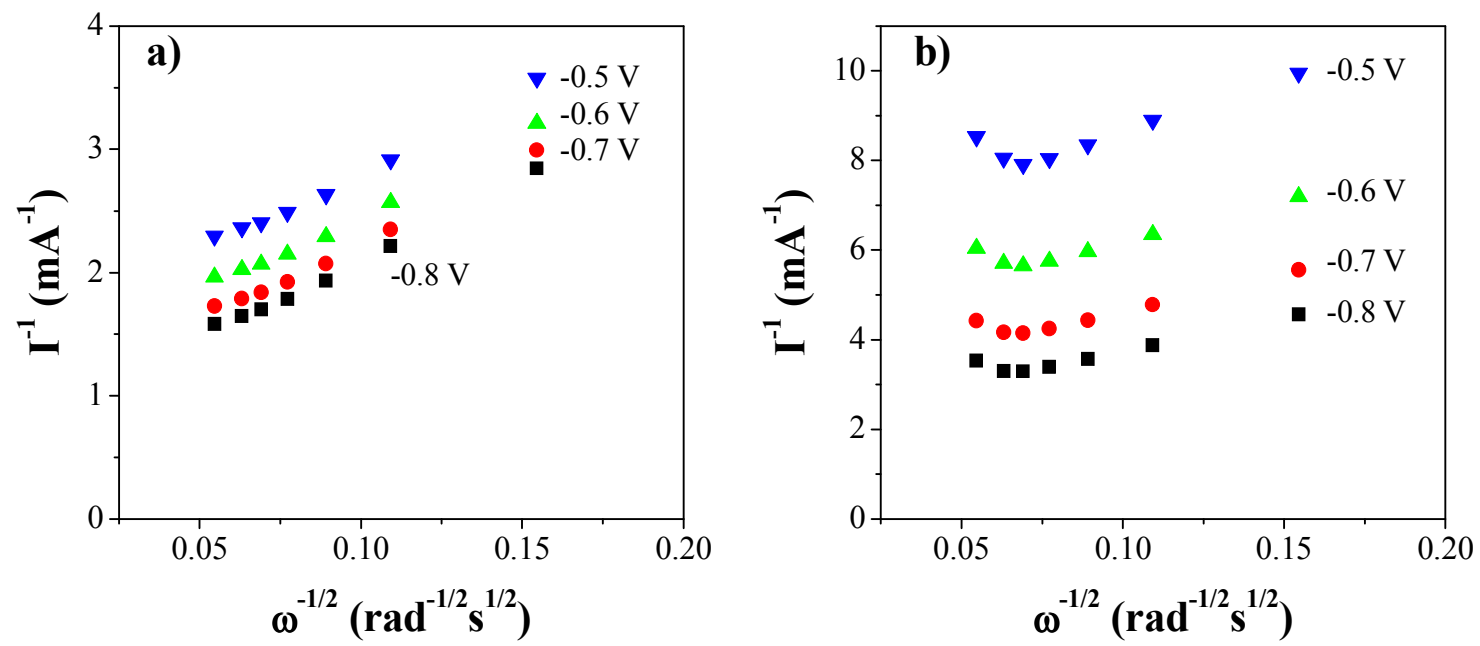

Figure S7. Koutecky-Levich plots of a) CN-SBA15 and b) C-SBA15 in $\mathrm{O}_{2}$-saturated PBS $\mathrm{pH} 6.86$ at different potentials (vs. $\mathrm{Ag} / \mathrm{AgCl}$ ).

The current intensity I on the rotating disk electrode can be obtained from the KouteckyLevich equation $\frac{1}{I}=\frac{1}{I_{k}}+\frac{1}{I_{l e v}}$ where $I_{k}$ is the kinetic current intensity and $I_{\text {lev }}$ is the Levich current: $I_{k}=n F k C_{0} ; I_{l e v}=0.62 n F A C_{0} D_{0}^{2 / 3} v^{-1 / 6} \omega^{1 / 2} . \mathrm{n}$ stands for the overall electron transfer number, $\mathrm{F}$ is the Faraday constant in $\mathrm{C} \mathrm{mol}^{-1}\left(96485 \mathrm{C} \mathrm{mol}^{-1}\right), \mathrm{A}$ is the area of the electrode in $\mathrm{cm}^{2}, \mathrm{C}_{0}$ is the oxygen concentration in the electrolyte in $\mathrm{mol} \mathrm{cm}^{-3}$ (in the case of $\mathrm{O}_{2}$ saturated electrolyte, $\left.\mathrm{C}_{0}=1.2 \cdot 10^{-6} \mathrm{~mol} \mathrm{~cm} \mathrm{~cm}^{-3}\right), \mathrm{D}_{0}$ is the diffusion coefficient of oxygen in $\mathrm{cm}^{2} \mathrm{~s}^{-1}\left(2.7 \cdot 10^{-5}\right.$ $\left.\mathrm{cm}^{2} \mathrm{~s}^{-1}\right), v$ is the kinematic viscosity in $\mathrm{cm}^{2} \mathrm{~s}^{-1}\left(0.01 \mathrm{~cm}^{2} \mathrm{~s}^{-1}\right)$ and $\omega$ is the angular rotation rate in $\operatorname{rad~s}^{-1} 1$

\section{References}

(1) Su, Y.; Jiang, H.; Zhu, Y.; Zou, W.; Yang, X.; Chen, J.; Li, C. Hierarchical porous iron and nitrogen co-doped carbons as efficient oxygen reduction electrocatalysts in neutral media. J. Power Sources 2014, 265, 246-253. 